\title{
DIFFERENCES BETWEEN PSYCHOTHERAPY AND COUNSELLING. WHO IS LOOKING FOR AND WHO NEEDS THEM?
}

\section{Primož Rakovec}

School of Advanced Social Studies, Slovenia

E-mail: primoz.rakovec@fuds.si

Abstract: According to statistical forecasts in modern societies is trend of mental disorders growth, especially anxiety and depression. At the same time there will be probably present higher demands for professional psychosocial support. Psychotherapy and counselling as talking interventions are part of the psychosocial support, needed when people can't resolve their (mental) problems by themselves. The article deals with the question about differneces between those two professions. Are those differences artificial, is there any argumented facts in favour of different proponents? For this purpose we have examined different definitions of counselling and psychotherapy, training standards, techniques and skills, ethical standards, treatment outcomes, depth of treatment and clients expiriences.

Key-words: counselling, psychotherapy, differences, similarities

\section{Introduction}

Counselling and psychotherapy, as talking interventions, are ways of responding to a wide range of human needs. Counselling and psychotherapy provide opportunities for those seeking help to work towards ways of living in more satisfying and resourceful ways. In their current form, counselling and psychotherapy are less than 100 years old, but they have roots in much older ways of providing help and care. Counselling and psychotherapy have developed in order to respond to modern circumstances. They are living practices which are open to change and which evolve in response to changing needs. Consequently, it is impossible to define counselling and psychotherapy once and for all.

Counselling as a profession grew out of the progressive guidance movement of the early 1900s. Its emphasis was on prevention and purposefulness - on helping individuals of all ages and stages avoid making bad choices in life while finding meaning, direction, and fulfilment in what 
they did. Today professional counselling encompasses within its practice clinicians who still focus on the avoidance of problems and the promotion of growth, but the profession is much more than that. The focus on wellness, development, mindfulness, meaningfulness, and remediation of mental disorders is the hallmark of counselling for individuals, groups, couples, and families across the life span (Gladding 2014).

Traditionally, psychotherapy has focused on serious problems associated with intrapsychic, internal, and personal issues and conflicts. It has dealt with the recovery of adequacy (Casey 1996). As such, psychotherapy, especially analytically based therapy, has emphasized (1) the past more than the present, (2) insight more than change, (3) the detachment of the therapist, and (4) the therapist's role as an expert. In addition, psychotherapy has historically involved a long-term relationship (20 to 40 sessions over a period of 6 months to 2 years) that concentrated on reconstructive change as opposed to a more short-term relationship ( 8 to 12 sessions spread over a period of less than 6 months). Psychotherapy has also been more of a process associated with inpatient settings - some of which are residential, such as mental hospitals - as opposed to outpatient settings - some of which are nonresidential, such as community agencies. However, in more modern times, the distinction between psychotherapy and counselling has blurred, and professionals who provide clinical services often determine whether clients receive counselling or psychotherapy. Some counselling theories are commonly referred to as therapies as well and can be used in multiple settings. Therefore, the similarities in the counselling and psychotherapy processes often overlap (Gladding 2014).

\section{Differences or similarities?}

\subsection{Accepted definitions of counselling and psychotherapy}

To find an unambiguous answer on question "What are the differences between counselling and psychotherapy?" is not simple, if we want to find argumented answers, not just opinions and assumptions. If we just look at definitions of psychotherapy and counselling, we can find more similarities than differences. European Association for Counselling (EAC) defines that profession as an interactive learning process contracted between counsellor(s) and client(s), be they individuals, families, groups or institutions, which approaches in a holistic way, social, cultural, economic and/or emotional issues. Counselling may be concerned with addressing and resolving specific problems, making decisions, coping with crisis, improving 
relationships, developmental issues, promoting and developing personal awareness, working with feelings, thoughts, perceptions and internal or external conflict. The overall aim is to provide clients with opportunities to work in self-defined ways, towards living in more satisfying and resourceful ways as individuals and as members of the broader society (EAC 2013). American Counselling Association (ACA) defined counselling as a professional relationship that empowers diverse individuals, families, and groups to accomplish mental health, wellness, education, and career goals (Kaplan, Tarvydas and Gladding 2014). European Association for Psychotherapy defines the practice of psychotherapy as the comprehensive, conscious and planned treatment of psychosocial, psychosomatic and behavioural disturbances or states of suffering with scientific psychotherapeutic methods, through an interaction between one or more persons being treated, and one or more psychotherapists, with the aim of relieving disturbing attitudes to change, and to promote the maturation, development and health of the treated person. It requires both a general and a specific training/education (EAP 2003). As we can see, all three definitions expose professional relationship between trained or educated professional(s) and client(s) with final goal to rise client's satisfaction level on different life areas, including mental health.

\subsection{Trend of integration}

Next argument that speaks in favour of similarity between counselling and psychotherapy is worldwide trend of psychotherapy and counselling associations merging and their argumentation about similarities between those two professions. Irish Association for Counselling and Psychotherapy (IACP) position is that there is no difference between counselling and psychotherapy as they have found no practical or research evidence to support differentiation. IACP describes counselling and psychotherapy in the following way: counselling/psychotherapy is for anybody. It can be of great support in times of crisis or change. Both counselling and psychotherapy involve the provision of professional assistance to people who are experiencing personal issues, in order to help alleviate those difficulties. Counselling tends to deal more with immediate issues that may have arisen more recently e.g. bereavement or relationship breakdown. Psychotherapy tends to deal with deeper, more longterm issues that may be rooted in the past e.g. a trauma, or, serious mistreatment where the effects of such are ongoing. Counselling and psychotherapy are terms that overlap heavily and are often used interchangeably. They incorporate the giving of attention and respect in a confidential relationship. It provides an opportunity to explore, 
discover and clarify ways of living more resourcefully towards greater wellbeing. Stress, anxiety, bereavement, addiction and relationship issues are some of the reasons why people engage the services of a counsellor/psychotherapist. (IACP 2013). Although Psychotherapy \& Counselling Federation of Australia (PACFA) shares similar opinion, PACFA have found some differences: counselling and psychotherapy overlap considerably, but there are also recognised differences. While the work of counsellors and psychotherapists with clients may be of considerable depth, the focus of counselling is more likely to be on specific problems, changes in life adjustments and fostering clients' wellbeing. Psychotherapy is more concerned with the restructuring of the personality or self and the development of insight. At advanced levels of training, counselling has a greater overlap with psychotherapy than at foundation levels (PACFA 2012). Having said that, the British Association for Counselling and Psychotherapy (BACP) have found no empirical evidence that there is a difference between counselling and psychotherapy. In terms of role, value and effectiveness, BACP believes that each occupational area has equal value. BACP's research committee is an independent group, comprised of psychiatrists, psychologists, counsellors and psychotherapists from the UK and overseas and including several non BACP members and is tasked with offering independent advice on research issues to BACP. In 2006, the committee found there was no theoretical, practical or research rationale for distinguishing between counsellors and psychotherapists. (BACP 2009).

\subsection{Possible ways of distinguishing counselling from psychotherapy}

Some ways of distinguishing counselling from psychotherapy include: (1) psychotherapy focuses on personality change of some sort, while counselling focuses on helping clients use existing resources for coping with life better, (2) they are the same qualitatively, but differ only quantitatively in that, therapists listen more and engage in less informing, advising and explaining than counsellors, and (3) psychotherapy deals with more severe disturbance and is more medical term than counselling (Corsini 2008).

But those differences are artificial in the light of the fact that counselling was advice giving orientated just in the beginning stage (the end of 19. and the beginning of 20. century) (Nugent and Karyn 2009). In the 1942 Carl Rogers published his book Counselling and Psychotherapy, which challenged the counsellor-centred approach of Williamson as well as major tenets of Freudian psychoanalysis. Rogers emphasized the importance of the client, espousing a nondirective approach to counselling. His ideas were both widely accepted and harshly criticized. Rogers advocated giving clients 
responsibility for their own growth. He thought that if clients had an opportunity to be accepted and listened to, then they would begin to know themselves better and become more congruent. He described the role of the professional helper as being nonjudgmental and accepting. Thus, the helper served as a mirror, reflecting the verbal and emotional manifestations of the client (Gladding 2014; Stepišnik Perdih, 2018).

When we talk about listening skills, we must be fair enough to admit that active listening is probably the central skill in developing and maintaining counselling relationship, not just in psychotherapy. Active listening in counselling process has a number of important consequences: (1) establishing rapport, (2) establishing trust, (3) bridging differences, (4) helping clients to disclose, (5) helping clients to experience feelings, (6) gathering information, (7) creating an influence base, and (8) helping clients to assume responsibility (Nelson-Jones 2014).

Information giving or psychoeducation is important part of counselling and psychotherapy processes. We know that $10 \%$ of clients with panic attacks feel better and don't need further psychotherapeutic treatment, when they get detailed information about this disorder (Kocmur 1999). Psychoeducation is a practice that provide the opportunity to learn about the lifestyle adjustments and new skills needed to manage the condition, so that a person might become a more active participant in the treatment process (Lukens and McFarlane 2004; Stafford and Colom 2013). It is an approach to the treatment of mental illness that has developed over the past four decades (Goldman 1988; Hatfield 1988), and is concerned with how to influence a person's internal world of thoughts and feelings as a means to change behaviour (Bauml et al. 2006).

The term counselling may be just as appropriate as psychotherapy even in medical settings, and increasingly it has come to be viewed as either the same as or similar to psychotherapy (Nelson-Jones 2014). The term psychotherapy derives from Ancient Greek psyche (meaning breath, spirit, soul) and therapeia. When therapeia is translated as healing or medical treatment, it can have more medical hint. But Ancient Greek word therapeia can be also translated as attendance (Collins English Dictionary 2014). In that case psychotherapy is much more than just healing of the soul, it is not limited just in medical setting, and is more similar to counselling. Many psychologists, as Corey (2012) and Patterson (1986) use the terms counselling and psychotherapy interchangeably, and Patterson concludes that there are no essential differences upon which agreement can be reached. Both counselling and psychotherapy use the same theoretical models and stress the need to 
value the client as person, to listen sympathetically, to hear what is communicated, and to foster the capacity for self-help and responsibility.

In fact, although differences in the training of mental health professionals exist, over the years their professional duties have begun to overlap (Todd and Bohart2006). For instance, today, some school counsellors do therapy, counselling and clinical psychologists act as consultants to the schools, psychiatrists are social advocates, social workers and others can be psychoanalysts, mental health counsellors do family therapy, and psychologists vie for the right to prescribe psychotropic medications (Johnson 2009). The differences in the training of counselling and psychotherapy are more quantitative, than qualitative. For example the EAC Training standards predict three main pillars: (1) course work, (2) counselling practice under supervision, and (3) personal development. In course work are included: (1) clear understanding of a core theoretical model of counselling, (2) theories of personality, (3) theories of change or client movement, (4) models of human development, (5) understanding of psychological dysfunction, (6) understanding of ethics and professional practice, (7) the history of counselling and a study of at least two other counselling approaches, (8) study of a cultural differences and awareness processes (EAC 2013). European Association for Psychotherapy (EAP) describes three elements of basic professional training: (1) personal psychotherapeutic experience, (2) practical training, and (3) theoretical study which should include the following elements: (1) theories of human development throughout the life-cycle, (2) an understanding of other psychotherapeutic approaches, (3) a theory of change, (4) an understanding of social and cultural issues in relation to psychotherapy, (5) theories of psychopathology, and (6) theories of assessment and intervention (EAP 2012). But there are quantitative differences between counselling and psychotherapy training. Counselling training last minimum three years and includes 450 hours of theory, 450 hours of supervised counselling practice, and 50 hours of personal development (EAC 2013). Psychotherapy training last minimum four years and includes 500 - 800 hours of theory and methodology, 300 hours of psychotherapeutic work with clients under supervision, 150 hours of supervision, and 250 hours of self-experience (EAP 2012).

Both professions have ethical standards which are quite similar. The counselling approach values the integrity, authority and autonomy of the client. This is expressed in a skilled and professional way in the counselling relationship (EAC 2013). In psychotherapy individual diagnostic and therapeutic services are provided only in the context of a professional 
psychotherapeutic relationship (EAP 2012). Professional relationship and working alliance are most important parts of both professions. In the absence of professional relationship no intervention technique won't work. Lambert conducted an empirical analysis of common therapy factors. In his review, he identified the following four common factors and estimated how much each factor typically accounts for therapeutic change: therapeutic relationship (30\%), extratherapeutic change (40\%), expectancy (placebo effects; 15\%), techniques (15\%) (Lambert 1992).

Thorne (1992) makes a strong case suggesting that it is difficult to differentiate between counselling and psychotherapy on several grounds such as problems explored (huge overlaps), goals addressed (often similar), or the notion that psychotherapy is somehow more synonymous with unconscious work than counselling. Meta-analytic studies comparing counselling with cognitive behavioural therapy for depression suggest either broad equivalence of patient outcomes or, where differences do exist, that they are small (Barkham, Moller and Pybis 2017). Ward and colleagues reported comparisons between nondirective counselling and cognitive behavioural therapy for mixed anxiety and depression and found no significant difference in outcomes for the two therapies (Ward et al. 2000). Since 2013-14, Improving Access to Psychological Therapies programme (IAPT) have published annual reports comparing the number of referrals, average number of sessions and recovery rates between the available psychological therapies. As demonstrated in Table I, whilst a greater proportion of referrals (approximately 60-65\%) received CBT as compared with counselling, patient outcomes (i.e., recovery rates) have been virtually equivalent between those two interventions (Barkham, Moller and Pybis 2017).

Data demonstrate that for patients accessing interventions throughout the NHS, counselling is, to all intents and purposes, as effective as cognitive behavioural therapy in the treatment of depression for both moderate and severe levels of depression (Barkham, Moller and Pybis 2017). Cape and colleagues provide similar results. They include thirty-four studies of anxiety, depression and mixed common mental health problems treatment with brief cognitive behavioural therapy, problem solving therapy and counselling in their meta-analysis. The meta-analysis suggests that brief cognitive behavioural therapy, counselling and problem solving therapy were all effective. No significant difference was found between cognitive behavioural therapy, counselling and problem solving therapy outcomes (Cape et al. 2010). 
Table I: Data extracted from successive NHS digital reports on comparisons between cognitive behaviour therapy (CBT) and counselling/counselling for depression (CfD).

\begin{tabular}{lllll}
\hline Year & Intervention & $\begin{array}{l}\text { Number of } \\
\text { referrals for } \\
\text { depressive } \\
\text { disorder }\end{array}$ & $\begin{array}{l}\text { Average } \\
\text { number of } \\
\text { sessions }\end{array}$ & $\begin{array}{l}\text { Recovery } \\
\text { rate (\%) }\end{array}$ \\
\hline $2013-14$ & CBT & 21,622 & 5.7 & \\
& Counselling & 13,369 & 5.4 & 45,1 \\
$2014-15$ & CBT & 28,350 & 5.1 & 44,1 \\
& Counselling & 14,994 & 4.4 & 45,2 \\
$2015-16$ & CBT & 35,589 & 5.8 & 45,9 \\
& Counselling/CfD & 20,011 & 5.3 & 47,6 \\
\hline
\end{tabular}

Source: Barkham, Moller, and Pybis 2017

Data suggest clients accessing counselling attend fewer sessions on average than those accessing CBT (NHS Digital 2014, 2015, 2016; Pybis et al. 2017; Saxon et al. 2017). This suggests counselling may well be cheaper and therefore more cost-efficient than cognitive behavioural therapy as it achieves comparable patient outcomes.

As Thorne said addressed goals in counselling and psychotherapy are often similar (Thorne 1992). The final goal of counselling and psychotherapy is the same, helping clients to become their own counsellors or psychotherapists. Modern trends in counselling and psychotherapy tend to teach clients the skills and techniques which they can use independently in case of relapse of the problem(s) in the future. So clients can become their own counsellors or psychotherapists without lifelong dependence on counselling or psychotherapist professionals (Dryden 2006). Nowadays in the light of increasingly larger demands for time saving, lifelong dependency on psychotherapy and counselling are not appropriate anymore. In adjusting to those trends both professions have invited so called brief versions of clients treatment (Dryden 2006; Trower, Jones and Dryden 2016).

Argument that counsellors, in general, deal with less severe cases and psychotherapists with more severe ones, gains substance only when we are able to learn objectively how severity is defined and measured. How do health professionals know when a given problem falls within their area of expertise? How do they arrive at the conclusion that the problem is one which would benefit from counselling and not from psychotherapy, or from psychotherapy and not from counselling, or from both, or indeed from neither? Human 
problems cannot be arbitrarily dichotomized into severe and non-severe. The judgement of severity or non-severity, more often than not, is based on the experience of the health professional involved. Nor have human problems been objectively and precisely graded, ranging from the least severe to the most severe. No such gradations or distinctions have been formulated which would allow us to classify human problems along an objective scale of measurement. Therefore, for health professionals to decide on the severity of a problem, they would need to rely on their subjective judgement which of course, despite one's vast experience, is fallible. At any rate, to arrive at a clinical judgement concerning the severity or otherwise of a given client's problems, disorders, conflicts, emotional crises or whatever, a counsellor or psychotherapist would need to be experienced and, more importantly, competent. Who one would classify as a 'competent counsellor' is not an easy question to answer. One might have years of experience and still remain hopelessly muddled and incompetent. The competence of a counsellor is related to several factors, one of which is the ability of the counsellor to get to the root of the client's problem - the diagnostic problem (Laungani 2004).

Example of how difficult it is to arrive at a correct diagnosis of a psychological disorder, is the Rosenhan study from 1973. As part of the study, he sent eight pseudo-patients (including himself) to different American psychiatric hospitals, where they presented to the psychiatrist who interviewed them a single set of symptoms, such as, 'I feel empty', 'I hear a thud', 'I feel hollow' etc. All the pseudopatients, without exception, were diagnosed as suffering from schizophrenia and were admitted to hospital. The pseudo-patients fooled the doctors, the psychiatrists on the ward. But what was even more remarkable was the fact that they were instantly recognized as being pseudo-patients by 35 out of a total of 118 real patients. The genuine patients were convinced that the pseudo-patients were journalists, professors or some such type of person, in search of a story. It is clear that the reliability and validity of a variety of diagnostic techniques remains an unresolved issue (Rosenhan 1973; Laungani 2004).

At last, there could not be a big difference between counselling and psychotherapy if both approaches arise from the same philosophical and theoretical frames. If we look at cognitive behavioural therapy and cognitive behavioural counselling, for example, both approaches derive from stoic philosophy, and employ cognitive, behavioural and mindfulness techniques (Robertson 2010). According to Elliot and Williams research for clients seem to have little regard to counselling or psychotherapeutic theory or technique, but do recognise the importance of the person who is the therapist or counselor, and the relationship they have with them. In those clients endorse 
the view that it is the relationship rather than a particular way-of-working which carries therapeutic gain. Clients value talking to someone who is warm and listens in a non-judgemental manner (Elliott and Williams 2003). In that context Kwiatkowskis' (1998) questioning who is looking for and making differences between counselling and psychotherapy, whether they are professionals or clients, is in the right place. His conclusion is that differences between those professions are small, depend on the context and perception, not on content, skills and process. He suggests new paradigm, which could combine and calm down professionals of both fields and usage of the term 'counselling psychotherapist'.

\section{Conclusion}

When we are talking about professional counselling and psychotherapy within the same approach (e.g. psychoanalytic, Adlerian, existential, personcentred, gestalt, reality, cognitive behavioural, integrative, family systems, integrative ...) there is no doubt that both professions arise from the same philosophical and theoretical frames. As talking intrventions are based on strong relationship between counsellor(s)/psychotherapist(s) and client(s) with the main goal of intervention: help client(s) to improve their level of contentment and teach them to become their own counsellors/psychoterapists. Modern definitions of counselling and psychotherapy are expanded. Psychotherapy is not concentrated only on mental helth issues, it includes wide spectrum of humans' wellbeing. Counselling is not just an advice giving as it was in the beginning stage. Novadays counsellors are trained for empowering clients to accomplish mental health goals and other given goals on different life areas. When we are talking about training, we must admit, that there are some differences between those two interventions. Quantitative training standards are higher for psychotherapy professions, while qualitative standards are much the same for counselling and psychotherapy. But those standards are just first step to become a professional counsellor or psychotherapist, after diploma follows process of lifelong learning.

Even researhes on psychotherapy and counselling (Ward et al. 2000; BACP 2009; Barkham, Moller, and Pybis 2017; Pybis et al. 2017) didn't find theoretical, practical or research rationale for distinguishing between counselling and psychotherapy. Data suggest counselling may well be cheaper and therefore more cost-efficient than (cognitive behavioural) psychotherapy as it achieves comparable client outcomes. 
Next, frequently mentioned difference is that psychotherapy deals with more severe disturbance and is more medical term than counselling. Quite misleading. If we look at the origin of the term psychotherapy carefully, we can see, that psychotherapy can also be attendance (like counselling is defined) not just client healing. Severity of cases on the other hand is never objective. Every problem is severe for the individual client. It is on counsellor or psychotherapist to judge if he is appropriate professional to help individual clinet with his severe problem.

As we have wrote, most important factor for clients' change is warm, confidential relationship between counselor(s) and client(s), used techniques are not half so important, but still they are the factor. There could not be warm and confidential relationship in counselling or therapeutic process without appropriate techniques or counsellors' micro skills (e.g. active listening, paraphrasing, openended questions, empathy, nonjudgemental acceptance ...) which are again the same in all counselling and psychotherapeutic approaches. Also other techiques (e.g. in cognitive behavioural approaches identifying and responding to automatic thoughts, intermediate and core beliefs, behavioural activation, relaxation techniques ...) are used for the same purpose in counselling and psychotherapy - facilitating clients' cognitive and behavioural change.

Finally, according to data clients don't care with who they work on their progress, counsellors or psychotherapist. Everything that count is personality, acceptance and readiness to listen. So we can assume that if there some differences between counselling and psychotherapy exist, that are more or less finesses. There are a lot of secular tries to differentiate those two professions. But when we eliminate opinions and assumptions, we can confirm more similarities than differences between those two professions. And if we conclude in Kwiatkowskis' manner, maybe now, twenty years after his attempt to unify those two professions, is appropriate time to stop vaisting energy for making and looking for differneces and start setting up the conditions for cooperative help to those who need help and are not upset whether there are some differences or not.

\section{References}

BACP (British Association for Counselling and Psychotherapy). 2009. Excerpt from the Report from the Research Committee, 10 May 2006. BACP Response to HPC Consultation. 
Bauml, Joseph, Teresa Frobose, Sybille Kraemer, Michael Rentrop, and Gabriele Pitschel-Walz. 2006. "Psychoeducation: A basic psychotherapeutic intervention for patients with schizophrenia and their families." Schizophrenia Bulletin 32: 1-9.

Barkham, Michael, Naomi P. Moller, and Joanne Pybis. 2017. "How should we evaluate research on counselling and the treatment of depression? A case study on how the National Institute for Health and Care Excellence's draft 2018 guideline for depression considered what counts as best evidence." Counselling and Psychotherapy Research 17 (4): 253-268.

Cape, John, Craig Whittington, Marta Buszewicz, Paul Wallace, and Lisa Underwood. 2010. "Research article Brief psychological therapies for anxiety and depression in primary care: meta-analysis and meta-regression." $B M C$ Medicine 8 (38): 1-13.

Casey, Jean M. 1996. Gail F. Farwell: “A developmentalist who lives his ideas.” The School Counsellor 43: 174-180.

Collins English Dictionary - Complete and Unabridged, 12th Edition 2014. S.v. "therapia." https://www.thefreedictionary.com/therapia. Accessed December 12, 2018.

Corey, Gerald. 2012. Theory and Practice of Counseling and Psychotherapy. 9th Ed. Belmont: Brooks/Cole.

Corsini, Raymond J. 2008. "Introduction." In Current Psychoterapies 8th Ed., edited by Raymond J. Corsini and Danny Wedding, 1-14. Belmont: Thomson Brooks/Cole.

Dryden, Windy. 2006. Counselling in a Nutshell. London: Sage.

EAC (European Association for Counselling). 2013. Training Standards, Accreditation and Ethical Charter. Newcastle upon Tyne: EAC.

EAP (European Association for Psychotherapy). 2003. Definition of the profession of Psychotherapy. Appendix 1 to the Board Minutes, Siracuse 17th to 18 th of October 2003.

https://www.europsyche.org/contents/13219/definition-of-the-professionof-psychotherapy. Accessed November 3, 2018. 
EAP (European Association for Psychotherapy). 2012. The European Certificate for Psychotherapy.

http://www.europsyche.org/download/cms/100510/ECPdocument_versio n-5-0-voted-AGM-Valencia-July-2012.pdf. Accessed December 13, 2018

Elliott, Mark and David Williams. 2003. "The Client Experience of Counselling and Psychotherapy." Counselling Psychology Review 18 (1): 34-38.

Gladding, Samuel T. 2014. Counseling. A Comprehensive Profession. 7th Ed. Harlow: Pearson.

Goldman, Charles R. 1988. "Toward a definition of psychoeducation.” Hospital and Community Psychiatry 39: 666-667.

Hatfield, Agnes B. 1988. "Issues in psychoeducation for families of the mentally Ill." International Journal of Mental Health 17: 48-64.

IACP (The Irish Association for Counselling and Psychotherapy). 2013. The Irish Association for Counselling and Psychotherapy (IACP) Position Paper on Statutory Regulation and the difference between Counselling and Psychotherapy. https://iacp.ie/files/UserFiles/News-Links/IACP-PositionPaper-Nov-20-2013.pdf. Accessed September 12, 2018.

Johnson, Julia. 2009. "Whether states should create prescription power for psychologists." Law and psychology review 33: 167-178.

Kaplan, David M, Vilia M. Tarvydas, and Samuel T. Gladding. 2014. “20/20: A Vision for the Future of Counseling: The New Consensus Definition of Counseling." Journal of Counseling \& Development 92: 366-372.

Kocmur, Marga. 1999. "Nevrotske, stresne in somatomorfne motnje." In Psihiatrija, edited by Martina Tomori and Slavko Ziherl, 229-258. Ljubljana: Medicinska fakulteta.

Kwiatkowski, Richard. 1998. "Counselling and psychotherapy: are they different and should we care?" Counselling Psychology Quarterly 11 (1): 5-14.

Lambert, Michael J. 1992. "Implications of outcome research for psychotherapy integration." In Handbook of psychotherapy integration, edited by John C. Norcross and Marvin R. Goldfried, 94-129. New York: Basic Books. 
Laungani, Pittu. 2004. Asian Perspectives in Counselling and Psychotherapy. New York: Brunner-Routledge.

Lukens, Ellen P. and William R. McFarlane. 2004. "Psychoeducation as evidence-based practice: Considerations for practice, research and policy." Brief Treatment and Crisis Intervention 4: 205-225.

Nelson - Jones, Richard. 2014. Practical Counselling and Helping Skills. London: Sage.

NHS Digital. 2014. Psychological therapies: Annual report on the use of IAPT services. England, 2013-2014.

http://content.digital.nhs.uk/catalogue/PUB14899.

NHS Digital. 2015. Psychological therapies: Annual report on the use of IAPT services. England, 2014-2015. Retrieved from http://content.digital.nhs.uk/ catalogue/PUB19098.

NHS Digital. 2016. Psychological therapies: Annual report on the use of IAPT services. England, 2015-2016.

http://content.digital.nhs.uk/pubs/psycther1516.

Nugent, Frank A. and Karyn D. Jones. 2009. Introduction to the Profession of Counseling, 5th Ed. Harlow: Pearson.

PACFA (Psychotherapy \& Counseling Federation of Australia). 2012. Definition of Counseling and Psychotherapy. http://www.pacfa.org.au/wpcontent/uploads/2012/10/Definition-of-Counselling-and-Psychotherapy2012.pdf. Accessed September 12, 2018.

Patterson, Holden C. 1986. Theories of Counseling and Psychotherapy 4th Ed. New York: Harper \& Row.

Pybis, Jo, David Saxon, Andy Hill, and Michael Barkham. 2017. "The comparative effectiveness and efficiency of cognitive behaviour therapy and counselling in the treatment of depression: evidence from the 2nd UK national audit of psychological therapies." BMC Psychiatry 17: 215. 
Robertson, Donald. 2010. The Philosophy of CBT. Stoic Philosophy as Rational and Cognitive Psychotherapy. London: Karnac Books Ltd.

Rosenhan, David L. 1973. “On being sane in insane places.” Science 179: 250258.

Saxon, Ashley D., Kate Ashley, Lindsey Bishop-Edwards, Janice Connell, Phillippa Harrison, Sally Ohlsen, Gillian E. Hardy, Stephen Kellett, Clara Mukuria, Toni Mank, Peter Bower, Mike Bradburn, John Brazier, Robert Elliott, Lynne Gabriel, Michael King, Stephen Pilling, Sue Shaw, Glenn Waller and Michael. 2017. "A pragmatic randomized controlled trial assessing the non-inferiority of counselling for depression versus cognitive-behaviour therapy for patients in primary care meeting a diagnosis of moderate or severe depression (PRaCTICED): A study protocol for a randomized controlled trial." Trials 18: 93.

Stafford, Nick and Francesco Colom. 2013. "Purpose and effectiveness of psychoeducation in patients with bipolar disorder in a bipolar clinic setting." Acta Psychiatrica Scandinavica 127: 11-18.

Stepišnik Perdih, Tjaša. 2018. Čustveno procesiranje in relacijska zakonska in družinska terapija. Kairos 3-4 (12).

Thorne, Brian. 1992. "Psychotherapy and counselling: the quest for differences." Counselling 3: 244-248.

Todd, Judith and Arthur C. Bohart. 2006. Foundations of clinical and counseling psychology. 4th ed. Long Grove: Waveland Press.

Trower, Peter, Jason Jones in Windy Dryden. 2016. CBC in action. 3rd Ed. London: Sage.

Ward, Elanie, Michael King, Margaret Lloyd, Peter Bower, Bonnie Sibbald, Sharon Farrely, Mark Gabbay, Nicholas Tarier, Julia Addington-Hall. 2000. "Randomised controlled trial of non-directive counselling, cognitivebehaviour therapy, and usual general practitioner care for patients with depression. I: clinical effectiveness." BMJ 321: 1383-1388. 